\title{
Arte, cultura e política no movimento estudantil brasileiro: uma combinação necessária
}

\author{
Art, culture and politics in the Brazilian student movement: a \\ necessary combination
}

\section{Renato da Silva Della Vechia}

\section{Resumo}

Este artigo busca resgatar algumas experiências de articulação entre a arte e a cultura com a atuação de entidades vinculadas ao movimento estudantil. Analisa o papel que o Centro Popular de Cultura (CPC) da União Nacional dos Estudantes (UNE) desempenhou durante o conturbado período que antecedeu ao golpe militar no Brasil, alguns debates relacionados a concepçóes sobre o papel da arte, bem como algumas tentativas de utilização de expressóes artísticas como forma de romper o isolamento a que as entidades estudantis foram submetidas após a intervenção militar no país. Por fim, resgata o papel que a questão cultural desempenhou no processo de redemocratização no contexto do Movimento Estudantil Gaúcho a partir da organização de um grande encontro em Caxias do Sul, denominado Cio da Terra e organizado pela União Estadual de Estudantes do Rio Grande do Sul (UEE/RS).

\section{Palavras-chave}

Movimento Estudantil; Arte; Cultura; Centro Popular de Cultura (CPC); Cio da Terra.

\begin{abstract}
This article seeks to analyze some political experiences articulated between art and culture with the performance of organizations linked with the Brazilian student movement. It examines the role that the Popular Culture Center (CPC), a branch of the National Student Union (UNE), played during the troubled period preceding the military coup d'état in the country. It focuses on some specific heated debates carried out by the members of those organizations about the different perspectives of the political role of art. It also examines some efforts of Centre, which attempted to use artistic expression as a way to break up the political isolation that student bodies were submitted because of the military intervention in Brazil. Lastly, it emphasizes the role that culture played in the Brazilian redemocratization process, specifically within the context of the Gaucho Student Movement, following the meeting in Caxias do Sul city named "Cio da Terra", organized by the Union of Students of Rio Grande do Sul (UEE/RS).
\end{abstract}

\section{Keywords}

Student Movement; Art; Culture; Cultural Popular Center (CPC); Cio da Terra. 


\section{Introdução}

A articulação entre arte e política não é algo comum no campo da política, ao menos não enquanto espaço de construção de novas relações sociais. Muitas vezes a arte foi utilizada de forma instrumental ou de forma pontual. Quando trabalhamos especificamente com o movimento estudantil enquanto um espaço específico de luta política, essa questão também não é muito diferente. No entanto, pela própria condição de seus atores (juventude), em alguns momentos essa relação pôde ser trabalhada de forma distinta.

Nesta perspectiva, o objetivo deste artigo é o de examinar a relação que em alguns momentos se constituiu entre as entidades representativas de estudantes (UNE - União Nacional de Estudantes, UEEs - Uniôes Estaduais de Estudantes e DCEs Diretórios Centrais de Estudantes) e a constituição de espaços culturais onde a juventude estudantil (notadamente universitários) pudessem se expressar.

Especificamente, buscamos analisar o papel que o Centro Popular de Cultura (CPC) cumpriu no período anterior ao golpe militar no Brasil; bem como algumas outras experiências mais localizadas durante o período militar e por fim analisar o papel que o $1^{\circ}$ Encontro da Juventude Gaúcha (Cio da Terra), desempenhou durante o processo de redemocratização no contexto do Rio Grande do Sul, através de uma iniciativa da União Estadual de Estudante (UEE/RS).

Para alcançarmos os objetivos propostos, buscamos documentos e bibliografia referentes ao tema, bem como reportagens, blogs e informaçóes on-line. No entanto, a base principal desse artigo é parte constituinte da Tese de Doutorado do autor, intitulada "O Ressurgimento do Movimento Estudantil Gaúcho no processo de Redemocratização: As Tendências Estudantis e seu papel (1977/1985)", a qual foi apresentada no Programa de Pós-Graduação em Ciência Política da UFRGS em 2011 (VECHIA, 2011).

$\mathrm{O}$ artigo está estruturado em quatro partes. Na primeira analisamos o papel que o Centro Popular de Cultura da UNE desempenhou no período anterior ao golpe militar no Brasil que se instaurou em 1964. Na segunda parte, buscamos apresentar algumas das concepçóes presentes sobre o papel da arte no processo político em curso na época. A terceira apresenta algumas experiências localizadas em que o movimento estudantil brasileiro ainda tentou resgatar o papel da arte enquanto um instrumento de mobilização política dentro dos limites possíveis no contexto do período militar. Por fim, na última parte, buscamos apresentar a experiência da organização do $1^{\circ}$ Encontro da Juventude Gaúcha (Cio da Terra), experiência que aconteceu na cidade de Caxias do Sul/RS, durante o período da redemocratização do Brasil. 


\section{A Experiência do CPC da UNE}

No quadro do movimento estudantil brasileiro, possivelmente a experiência melhor sucedida no que diz respeito à relação entre movimento estudantil e arte e cultura, e que também maior impacto trouxe às futuras gerações, tenha sido a criação do CPC da UNE.

Pode-se dizer que o CPC foi um movimento cultural que surgiu a princípio no Rio de Janeiro e que se espalhou por todo o país. Surgiu através de jovens intelectuais, na sua maioria estudantes e que viam a necessidade de criar uma cultura popular, ou seja, uma cultura engajada, que fosse um instrumento de politizaçáo para o povo, uma cultura que pudesse se contrapor a das classes dominantes.

Embora a criação formal do CPC tivesse ocorrido em dezembro de 1961, somente em 8 de março $^{1}$ de 1962 é que seu regimento interno foi submetido a uma Assembléia Geral. O CPC, que era o órgão cultural da UNE, possuía autonomia administrativa e financeira. Essa autonomia não ocasionou problemas maiores enquanto o movimento estudantil era coeso, mas com o surgimento de diversas organizações político-partidárias e a consequente divisão do movimento estudantil, surgiu com mais força a luta pela hegemonia do movimento, o que provocou conflitos entre a UNE e o CPC.

Em termos financeiros, o CPC sobreviveu de contribuições individuais; de recursos governamentais (Serviço Nacional do Teatro, Ministério da Educação MEC, etc.); de doaçóes de empresários e políticos e principalmente de pagamentos contra a prestação de serviços, além de recursos resultantes de contratos políticos para shows em comícios. Somente o teatro de rua e o teatro para camponeses eram apresentados gratuitamente, nas demais atividades do CPC era cobrado ingresso.

O CPC era dividido em departamentos: departamento de teatro; de cinema; de música; de arquitetura; de artes plásticas; de administração; de alfabetização; de literatura e de relações, com funções específicas, como veremos abaixo.

\section{Departamento de Teatro}

O Departamento de Teatro, que reunia, entre outros nomes, Oduvaldo Vianna Filho, Augusto Boal, Gianfrancesco Guarnieri, Arnaldo Jabor, Flávio Migliaccio, Claudio Cavalcanti e Cecíl Thiré2, foi responsável pela construção de um teatro e ampliação da sede do CPC no prédio da UNE; pela construção e instalação elétrica e sonora de uma carreta rebocada por um jipe e transformável em palco para

\footnotetext{
${ }^{1}$ Dia Internacional da Mulher.

${ }^{2}$ Todos eles posteriormente foram grandes nomes da dramaturgia e da televisão brasileira.
} 
espetáculos de teatro de rua e pela produção e montagem de no mínimo 19 peças (número extra-oficial) que foram apresentadas inúmeras vezes e em diversos locais do país.

\section{Departamento de Cinema}

O Departamento de Cinema, que reuniu nomes como Leon Hirzman, Carlos Diegues, Marcos Farias, Glauber Rocha, Ruy Guerra e Nelson Pereira dos Santos, foi o responsável pela realização do filme longa-metragem "Cinco vezes Favela", o qual foi distribuído em todo o Brasil, além de ser o responsável pela realização de diversos documentários, rodados durante a UNE-Volante.

\section{Departamento de Música}

O Departamento de Música, que reuniu nomes como: Carlos Lira, Geraldo Vandré, Milton Nascimento, Chico Buarque e Carlos Castilho, gravou e distribuiu um long-playing ${ }^{3}$ intitulado "O povo canta", o qual induzia as pessoas a perceberem as causas das dificuldades pelas quais passavam; gravou o disco "Cantigas de eleiçáa", o qual denunciava a corrupçáo do poder econômico no processo eleitoral; realizou a I Noite de Música Popular Brasileira, apresentada no Teatro Municipal do Rio de Janeiro, com a presença de diversos intérpretes e compositores populares, além de ser responsável pela realização de diversos shows musicais em praças e teatros de bairros do Rio de Janeiro e participação nas duas UNE-Volantes.

\section{Departamento de Literatura}

Este Departamento foi o encarregado da publicação dos "Cadernos do Povo Brasileiro", que falavam de temas como a reforma agrária; greves; revolução brasileira; imperialismo, etc. No livro "O Centro Popular de Cultura da UNE", de Manoel Berlink (1984), consta existir 24 números desta coleção, mas ele reconhece que podem existir mais alguns que ele desconheça. Além dos "Cadernos do Povo Brasileiro", também foram publicados outros livros, na sua maioria cordéis.

Além das obras produzidas nos departamentos já citados, o CPC também foi responsável por outras atividades, e entre elas se destacam:

1. A criação de cursos de teatro, cinema, artes visuais e filosofia;

2. A participação na primeira UNE-Volante, excursão que durou três meses e que foi a todas as regióes do país. Durante a excursão o CPC apresentava shows, peças de teatro, filmes documentários e exposições gráficas e

\footnotetext{
${ }^{3}$ Disco de vinil grande.
} 
fotográficas sobre reforma agrária, remessa de lucros, política externa independente, voto do analfabeto e Petrobrás;

3. Criaçáo de CPCs nas principais cidades do país;

4. Fundação da PRODAC (Produtora e Distribuidora de Arte e Cultura), que era uma rede nacional de distribuição de discos, livros e revistas. A PRODAC tinha representantes em mais de 50 cidades e distribuía para todo o Brasil, além das publicações do CPC, as obras das Editoras Civilização Brasileira, Universitária e Fulgor;

5. Realização do I Festival de Cultura Popular;

6. Produção de peças, músicas, e cartazes para os CPCs estaduais.

\section{Debates sobre a relação entre Arte e Politica}

O CPC nasceu em um momento político bastante conturbado de nossa história, quando a ideologia nacionalista transpassava a sociedade e consolidava a idéia de um bloco nacional que abrangia todas as classes sociais. É a efervescência política da época que permitiu o surgimento do CPC como ação revolucionáriareformista dentro da cultura.

Os integrantes do CPC dividiam a arte em três tipos: arte do povo, arte popular e arte popular revolucionária.

A arte do povo, segundo Carlos Estevam,

[...] é predominantemente um produto das comunidades economicamente atrasadas e floresce de preferência no meio rural ou em áreas urbanas que ainda não atingiram as formas de vida que acompanham a industrialização. $\mathrm{O}$ traço que melhor a define é que nela o artista não se distingue da massa consumidora. Artistas e público vivem integrados no mesmo anonimato e o nível de elaboração artística é tão primário que o ato de criar não vai além de um simples ordenar os dados mais patentes da consciência popular atrasada [...] é tão desprovida de qualidade artística e de pretensóes culturais que nunca vai além de uma tentativa tosca e desajeitada de exprimir fatos triviais dados à sensibilidade mais embotada. É ingênua e retardatária e na realidade não tem outra função que a de satisfazer necessidades lúdicas e de ornamento (ESTEVAM, 1963 apud BERLINCK, 1984, p. 43). 
Para Estevam, a arte popular se distingue da do povo.

Não só pelo seu público que é constituído pela população dos centros urbanos desenvolvidos como também devido ao aparecimento de uma divisão do trabalho que faz da massa a receptora improdutiva de obras que foram criadas por um grupo profissionalizado de especialistas. Os artistas constituem assim um estrato social diferenciado de seu público, o qual se apresenta ao mercado como mero consumidor de bens cuja elaboração e divulgação escapam ao seu controle. A arte do povo e a arte popular, quando considerados de um ponto de vista cultural rigoroso, dificilmente poderiam merecer a denominaçáo de arte, por outro lado, quando considerados do ponto de vista do CPC, de modo algum podem merecer a denominação de popular ou do povo (ESTEVAM, 1963 apud BERLINCK, 1984, p. 43-44).

\title{
Ainda se referindo à arte popular, Carlos Estevam a considera
}

\begin{abstract}
Mais apurada e apresentando um grau de elaboração técnica superior, não consegue, entretanto, atingir o nível de dignidade artística que a credenciasse como experiência legítima no campo da arte, pois a finalidade que a orienta é a de oferecer ao público um passatempo, uma ocupação inconseqüente para o lazer, não se colocando para ela o projeto de enfrentar os problemas fundamentais da existência (ESTEVAM, 1963 apud BERLINCK, 1984, p. 44).
\end{abstract}

Para os integrantes do CPC, a única arte legítima era a arte política, engajada, aquela que possui conteúdo revolucionário. Para Estevam, a cultura desalienada admite que "desempenha um papel revolucionário na sociedade pelo simples fato de existir como cultura não falsificada" (ESTEVAM, 1963 apud BERLINCK, 1984, p.57). Ainda segundo Estevam, "só há cultura popular onde se produz o processo que transforma a consciência alienada em consciência revolucionária ativamente engajada na luta política" (ESTEVAM, 1963 apud BERLINCK, 1984, p. 68). Para Vianinha, "o teatro tinha de servir à luta do povo, como instrumento de sua conscientização e meio de sua organização” (BERLINCK, 1984, p. 21). Em 1959, Guarnieri afirmava que "não vejo outro caminho para uma dramaturgia voltada para os problemas de nossa gente, refletindo uma realidade objetiva, do que uma definição clara ao lado do proletariado, das massas exploradas" (BERLINCK, 1984, p. 17). Arnaldo Jabor, revendo sua participaçáo na época, afirmou que "a gente pensava que a fome era um caso de informação: se o povo fosse bem informado, aconteceria a revolução, sem nos 
darmos conta da extrema complexidade do problema” (JABOR, 1973 apud HOLLANDA, 1981, p. 26).

Estas afirmações vindas dos expoentes do CPC refletem claramente uma visão que dava uma grande importância à arte política como um instrumento revolucionário.

O Centro Popular de Cultura, embora tivesse tido uma grande importância na nossa produção cultural, cometeu alguns equívocos, os quais precisamos resgatar no sentido de evitar com que os mesmos sejam repetidos.

O primeiro deles foi o excessivo valor dado a arte como um instrumento revolucionário. Segundo o próprio Arnaldo Jabor, "o que ficou foi esta inédita, incrível, infantil, generosa, genialmente ridícula crença nos poderes transformadores da arte como força política, no mundo" (JABOR, 1973 apud HOLLANDA, 1981, p. 28). Outra crítica que é feita se refere à afirmação de Carlos Estevam, de que "fora da arte política, não há arte popular” (ESTEVAM, 1963 apud ORTIZ, 1981, p. 73). Para Renato Ortiz, esta afirmação "não somente empobrece a dimensão estética, como distancia o autor dos interesses populares, posto que todo aspecto náo imediatamente político é eliminado" (ORTIZ, 1979, p. 73). Ainda segundo Ortiz, podemos notar uma incoerência teórica do CPC, pois quando entra em discussão a questão do imperialismo cultural, o folclore, antes considerado "falsa cultura", passa a ser "veracidade" nacional, ou seja, em contraposição ao Rock, por exemplo, é apresentada a música folclórica como legítima representante de nossa cultura (ORTIZ, 1979).

Para Sebastião Uchôa Leite, o CPC, "ao considerar os fenômenos populares enquanto alienação, se aliena a esse mesmo conceito" (LEITE, 1965 apud ORTIZ, 1979, p.76), pois "definir as manifestaçôes populares como falsa consciência implica necessariamente elegerem-se arbitrariamente valores da veracidade e de autenticidade cultural" (ORTIZ, 1979, p.77).

Outra observação feita por Renato Ortiz é quanto a relação intelectual-massa. Segundo ele, na visão do CPC "são os intelectuais que levam cultura às massas. Falase sobre o povo, para o povo, mas dentro de uma perspectiva que permanece sempre como exterioridade" (ORTIZ, 1979, p. 73) . Relacionado a isto, Manoel Berlinck afirma que

\footnotetext{
${ }^{4}$ Essa concepção possivelmente é decorrente da concepção leninista (que por sua vez vem de Kautski, presente nas organizaçóes de esquerda da época, quando afirmavam que a consciência de classe vem de fora da classe para dentro).
} 
[...] seus membros, por não pertencerem às classes populares e por viverem numa sociedade autoritária, onde a distância entre as classes é muito grande, tinham uma visão exterior e isolada tanto da consciência popular como das possíveis maneiras de alterá-las (BERLINCK, 1984, p. 108).

\title{
Para Heloisa Buarque de Hollanda, o CPC
}

\begin{abstract}
ao reivindicar para o intelectual um lugar ao lado do povo, não apenas se faz paternalista, mas termina - de forma adequada à política da época - por escamotear as diferenças de classes, homogeneizando conceitualmente uma multiplicidade de contradiçóes e interesses" (HOLLANDA, 1981, p. 19).
\end{abstract}

Não podemos afirmar aqui qual o sentido dado à palavra "povo" pelos integrantes do CPC. Se o mesmo se referia ao "conjunto dos habitantes de um determinado país ou região”, a crítica feita por Heloísa (HOLLANDA, 1981, p. 19) tem fundamento. Caso contrário, ou seja, se o sentido de povo for o mesmo que Lênin definiu como "o conjunto dos explorados e oprimidos de uma dada formação social” (VÁRIOS, 1989, p. 57), esta crítica então perde seu sentido de ser.

Debates conceituais à parte, no que tange ao papel desempenhado pelo Centro Popular de Cultura nessa conjuntura, lembramos que em 1962, os estudantes universitários brasileiros deflagraram uma grande campanha por um outro modelo de universidade, momento em que o CPC teve um papel fundamental.

Os estudantes se posicionaram em defesa das liberdades democráticas nos campos social e econômico; engajavam-se na resistência ao golpe: preparavam-se para a possibilidade de uma guerra civil; abriam o debate para a problemática da universidade; apoiavam todas as reivindicaçóes populares contra pobreza, baixos salários, políticas inflacionárias; e buscavam o trabalho político com base na cultura popular, criando o CPC (Centro Popular de Cultura), que disseminava, por meio do teatro e da propaganda, os debates dos seminários estudantis (SOUSA, 1999, p. 39).

O instrumento utilizado para esta campanha (reforma educacional) foi a criação da UNE-Volante, que era uma caravana de 20 a 25 pessoas, composta pela diretoria da UNE e membros do CPC, que percorreu todas as regióes do país. A caravana, que se deslocava de aviáo, tinha o objetivo político de levar as proposiçóes do Seminário de Curitiba para os estudantes, abrindo um amplo processo de discussão acerca da participação de 1/3 dos estudantes nos órgãos colegiados. 
A diretoria da UNE visitou cerca de 250 faculdades, participou aproximadamente de 200 assembléias gerais e realizou inúmeras reunióes com dirigentes estudantis em todo o país.

Para sensibilizar os estudantes mais despolitizados, que não participavam das assembléias, o CPC da UNE fazia apresentações de peças teatrais que tinham como eixo a Reforma Universitária, além de tratar de questóes como a luta antiimperialista, a reforma agrária, etc.

A discussão a este respeito não ficou restrita aos limites da universidade, pois os setores conservadores, ao notarem que a campanha estava ganhando corpo, começaram a fazer uma violenta campanha contra a UNE. Esse ataque dos conservadores fez com que outros setores sociais se colocassem ao lado da reivindicação dos estudantes.

Ao final da excursão UNE-Volante, reuniu-se em São Luis do Maranhão o Conselho Nacional dos Estudantes, que avaliando o espírito de luta em que se encontravam os estudantes (em duas universidades os estudantes já estavam em greve), resolve dar um prazo às autoridades para que fossem atendidas as reivindicações. Esgotado o prazo e sem resposta por parte das autoridades competentes, é decretada uma greve geral em junho de 1962.

A greve por $1 / 3$ foi a maior já registrada pelo movimento estudantil brasileiro, até aquele momento, atingindo cerca de 40 universidades, o que representava mais de $90 \%$ dos estudantes na época. Durante o seu curso os estudantes permaneceram mobilizados, participando de manifestaçóes e discutindo a problemática da Universidade. Se não conseguiu que todas as reivindicações fossem atendidas, serviu como referência à disputa pela construção de um outro modelo de universidade.

\section{Outras experiências culturais no Movimento Estudantil Brasileiro}

As "marcas" do CPC não se fizeram presentes apenas enquanto um instrumento de mobilização por parte da diretoria da UNE. Seja por ter se "enraizado" no movimento estudantil de forma mais geral no país, seja pelas questóes levantadas e que continuaram a ter repercussão, mesmo após o golpe militar de 1964. O movimento estudantil de Natal, no Rio Grande do Norte também construiu seu espaço cultural/estudantil, bem como outros estados também o fizeram. 
[...] a exemplo do que ocorria em vários Estados do Brasil, nasceu em Natal, no dia 19 de novembro de 1962, o Centro de Cultura Popular [...]. O CCP nasceu por inspiração da UNE, que na época defendia por todo o Brasil a idéia de criação de Centros Populares de Cultura, experiência iniciada no Rio de Janeiro por um grupo de atores profissionais, fruto de uma idéia surgida durante excursão do Teatro de Arena de São Paulo (SILVA, 1989, p. 102).

O golpe militar instaurado no Brasil buscou acabar com essas experiências culturais que tinham um forte conteúdo político naquele contexto. Não só o CPC da UNE foi extinto, também iniciativas locais sofreram as conseqüências do autoritarismo estatal.

Através de um trabalho contínuo realizado em acampamentos escolares e junto a entidades ou instituiçóes representativas dos trabalhadores, o CCP contribuiu para a discussão de temas relevantes da sociedade brasileira, mas teve vida efêmera. Em abril de 1964, sem completar dois anos de existência, suas atividades foram encerradas (SILVA, 1989, p. 104).

No entanto, embora entidades estudantis e até mesmo entidades de cunho cultural tenham sido "fechadas" a partir do momento em que foram consideradas ilegais (entidades estudantis) ou até mesmo em função de temor a possíveis represálias, o elemento cultural presente no imaginário da juventude da época continuou sendo um fortíssimo componente da luta por transformaçôes políticas e culturais em nossa sociedade. Para José Dirceu e Vladimir Palmeira,

Se não fosse o golpe, se tivéssemos conseguido redemocratizar o país em 67-68, teríamos feito uma revolução cultural maravilhosa, uma segunda Semana de Arte Moderna, um turbilhão de criatividade. Por isso digo que a geração de 68 foi um estado de espírito. Embora tenhamos sido derrotados politicamente - a ditadura continuou firme por muito anos -, nós mudamos a cara do país. Porque o movimento estudantil também era música, teatro, cineclube... era cultura, linguagem, propostas inovadoras: não haveria o cinema novo sem o movimento estudantil e seu público, nem o teatro de vanguarda, a música popular, as artes plásticas. Toda a produção cultural e artística do Brasil, tal como a conhecemos hoje, seria outra sem aquela extraordinária explosão de criatividade (DIRCEU e PALMEIRA, 1998, p. 26).

Como vimos, mesmo após o golpe militar, muitas experiências culturais se mantiveram articuladas com as entidades estudantis. Em São Paulo, dois teatros 
universitários tiveram um papel importante na vanguarda cultural: o TUCA (Teatro da Universidade Católica de São Paulo) e o TUSP (Teatro da Universidade de São Paulo). Os diversos Teatros de Arena, embora não diretamente vinculados às entidades estudantis também foram importantes espaços dessa disputa. Em Alagoas, o movimento estudantil construiu o Teatro Universitário de Alagoas, em 1968. Nesse mesmo ano organizaram o I Festival Universitário de Música Popular Brasileiro, sendo que o II Festival de MPB foi realizado em junho de 1970 e o III (e último), em dezembro de 1971. Os estudantes de Alagoas também organizaram a I Caravana da Cultura, inspirados no CPC.

Da mesma forma que os estudantes alagoanos, os recifenses organizaram o Festival Universitário Regional de Música Popular Brasileira, de caráter regional, no Teatro Santa Isabel, em novembro de 1970. Similar a essas experiências, esse período foi muito rico no universo da cultura e das artes no país inteiro. No entanto, na medida em que a repressão se intensifica, as manifestações artístico-culturais conhecidas como "contracultura" precisaram ser muito criativas para "burlar" a censura. Músicas com letras de duplo sentido, codinomes de autores e ou músicos muito conhecidos, etc.

Percebemos também que a medida que a repressão política se intensificou, os espaços públicos de festivais e atividades públicas começaram a diminuir de importância, seja pela dificuldade de realizá-los, seja pelo contexto da luta armada que mobilizou parcela significativa da juventude que atuava no movimento estudantil.

[...] os festivais são uma forte expressão cultural mas principalmente, um canal de manifestação política dentro da legalidade possível [...] procuravase não só o envolvimento dos universitários, mas do papel maceioense. Era como se os membros dos Diretórios e do Teatro Universitário Alagoano procurassem evitar - conscientemente ou por intuição - conduzir a prática estudantil para o isolamento trazidos pelas propostas de luta armada como forma de enfrentar o Regime Militar (OLIVEIRA, 1994, p. 98).

Mesmo não havendo mais espaços livres para grandes manifestaçôes culturais por parte da juventude brasileira, principalmente aquelas vinculadas à contracultura e ligadas aos movimentos políticos de contestação direta ao regime, durante todo o período militar a cultura e a arte mantiveram algum espaço, mesmo que marginal, como instrumentos de contestação não só ao regime autoritário, como também cultura de massas que tentava se implantar e alguns valores próprios de uma sociedade conservadora. Não é apenas coincidência que o movimento conhecido como Tropicália era tão temido pelo regime da época. A preocupação não era com o 
conteúdo das letras musicais, mas fundamentalmente com questôes comportamentais difundidas pelo movimento (cabelos compridos, barba, roupas coloridas e extravagantes para os costumes da época, amor livre, etc.). Esse debate/embate cultural/ideológico acompanhou todo o período militar e foi elemento importante no período da redemocratização do país.

\section{Cio da Terra: O "Woodstock Gaúcho" no periodo da Redemocratização}

No contexto da redemocratização, em que pese a continuidade de uma forte vinculação dos estudantes com as questôes culturais, o evento que mais impactou o movimento estudantil gaúcho a partir da perspectiva de vincular o movimento estudantil com a produção da arte e cultura, foi a realização do Cio da Terra ${ }^{5}$. Esse foi o nome de um evento cultural organizado pela UEE/RS em outubro de 1982, em Caxias do Sul, e que até hoje é lembrado por quem participou, ou até mesmo por pessoas que não chegaram a participar, mas que tiveram conhecimento do evento na época. Para Pepe Vargas, militante do movimento estudantil de Caxias do Sul e um dos responsáveis pelo núcleo de apoio no município,

O Cio da Terra foi uma espécie de acampamento da juventude do Fórum Social Mundial com vinte anos de antecedência. Abriu um processo de discussão para além das pautas políticas em sentido estreito. Várias dos temas que pautou se constituíram em movimentos sociais reconhecidos anos depois, mas não tinham ainda este status na época (VARGAS, 2011).

A condição de algo inédito era percebida por muitos dos que participaram do evento e que tinham participado em algum momento do movimento estudantil, como João Carlos Gastal que nesse momento estava saindo da universidade:

\footnotetext{
${ }^{5}$ Para maiores informaçóes, matérias de jornais, depoimentos e fotografias sobre o Cio da Terra, ver o blog "Cio da Terra" (CIO, 2008), ou a comunidade "Eu fui ao Cio da Terra" no Orkut (EU, 2011). Ainda existem pequenos vídeos (documentários) possíveis de serem localizados na internet.
} 
[...] foi um evento muito marcante, caracterizando algo até então inédito no movimento estudantil das décadas de 1970 e 1980, pois, até aquele momento, nenhuma iniciativa do movimento no âmbito cultural tivera dimensão e repercussão sequer longinquamente semelhante. O Cio da Terra constituiu um rompimento com posturas mais ortodoxas até então francamente hegemônicas no seio da esquerda como um todo e do movimento estudantil em particular, ao colocar em destaque temas alternativos de grande interesse para a juventude, como sexualidade, drogas, cultura, e prazer (GASTAL JUNIOR, 2011).

Até mesmo quem não participou diretamente do evento tem opinião sobre o mesmo. Para Abner Gomes,

Quem foi e me contou, me deixou a impressão que foi realmente um acontecimento perturbador, criativo, que alimentou a construção de novos valores para a vanguarda daquela época. - novas estéticas para os movimentos - novos movimentos novos encontros. Não acho que tenha tido um produto objetivo, acho que teve vários produtos disseminados uma influência de largo prazo. Acho que não teve um segundo porque não tinha como haver (GOMES, 2011).

Também conhecido como o woodstock gaúcho, expressão utilizada por parte da mídia na época, contou com um número de participantes e espectadores que ficou entre 10 a 15 mil. Não existem informaçóes seguras, ficando a critério de cada observador a estimativa. A própria diretoria da UEE perdeu o controle sobre a quantidade de pessoas que participaram. Centenas de pessoas entraram nos pavilhóes onde anualmente é realizada a Festa da Uva em Caxias através da cerca, sem pagar ingressos. A equipe de seguranças contratada para acompanhar o evento (80 pessoas) não foi suficiente para cobrir toda a área do local. Até mesmo pelo fato dos seguranças entrarem em greve na primeira noite do evento em função da má qualidade da alimentação que a empresa contratada ofereceu.

Fato curioso é o imaginário que o evento deixou até mesmo em pessoas que eram crianças na época e não participaram, mas que hoje fazem questão de opinar sobre o evento. Em um site do Orkut, existem depoimentos como o de uma pessoa que afirmou que "[...] moro e trabalho a uma quadra dos Pavilhóes, toda vez que olho praquele morro, me dá uma nostalgia do que nunca vivi - infelizmente nasci tarde (1972)" (EU, 2011). Ou então outra pessoa que se apresenta como Souza, que disse: 
Moro a 2 anos aqui em Caxias, moro ao lado dos pavilhóes. Ouvi falar da existência desse festival através de um vizinho aqui do condomínio, um quarentão que não dispensa um baseadinho. Sou careta com orgulho, mas não deixei de ficar fascinado com a descrição dele do evento. Quem diria que nosso estado já teve um Woodstock e ele foi do lado do meu condomínio. 1982 foi um ano mágico pra mim, tinha 10 anos e só sabia andar de monareta e colecionar figurinhas da Copa da Espanha (EU, 2011).

De forma similar, Sarah criou um blog sobre o Cio da Terra (SARAH, 2013), onde mostra surpresa por ser moradora de Caxias e não ter tido conhecimento antes a respeito do evento. Afirma que

[...] para você ver como às vezes a gente mora numa cidade há um tempão e não sabe nada sobre ela: faz muito pouco tempo que eu descobri que Caxias tinha sido palco de um woodstock (SARAH, 2013).

A comemoração dos 25 anos da realização do Cio da Terra em 2007 no município de Caxias, bem como reportagens na mídia local em 2012 quando dos 30 anos do evento, demonstram o impacto que o mesmo gerou no município.

O grande fluxo de jovens no evento, superando as expectativas iniciais, fez com que a estrutura de alimentação planejada não fosse suficiente, sendo que muitas pessoas saiam da área atrás de alimentos. Os armazéns da redondeza também não davam conta, sendo que frutas, queijo, salame, etc. também começaram a faltar nos locais próximos ao evento. A fila para os banheiros tinha uma duração média de 2 horas, sendo que alguns se deslocavam para um riacho próximo para tomar banho sem ter de enfrentar as filas.

Havia algum tipo de evento durante as 24 horas do dia, pois os shows acabavam na madrugada (perto das 5, 6 horas) e logo cedo outros estavam acordando e iniciando atividades como dança, capoeira, etc.

Apresentaram-se nos shows diversos nomes de diferentes estilos da área musical do país, como: Ednardo, Sivuca, Itamar Assunçáo, Jorge Mautner, Geraldo Azevedo, Bebeto Alves, Nelson Coelho de Castro, Vitor Ramil, Giba Giba, Grupo Tarancón, Grupo Saracura, Cenair Maicá, Nei Lisboa e outros.

Além dos shows musicais, houve exibição de filmes com debates; apresentação de peças de teatro, danças e debates dos mais variados temas como sexualidade, drogas, sindicalismo, revolução, educação, etc. 
Para dar conta da limpeza, os DCEs que davam sustentação política à diretoria da UEE na época definiam uma equipe de militantes que se revezavam duas vezes ao dia limpando o pátio, recolhendo papéis, copos plásticos, etc.

Foi construída uma verdadeira "cidade de barracas", onde as pessoas se revezavam entre dormir, ficar se aquecendo ao fogo à noite ou participando dos eventos. Como nem todos foram precavidos com barracas, alguns tinham barracas coletivas, onde se revezavam nos horários para dormir.

A segurança contratada foi instruída a garantir a segurança dos presentes mas não agir de forma repressora nas questôes ligadas a pequenos problemas, geralmente de caráter moral, como pessoas que andavam nuas ou uso de maconha.

Esse tipo de situação criou condições para que parte da mídia local denunciasse o evento como sendo um espaço de promiscuidade, onde a única preocupação seria com sexo e drogas. Radialistas locais faziam chamadas pedindo aos pais que não deixassem os filhos participar do evento ou que fossem ao local para retirá-los. Alguns chegavam a rotular o evento como "festival de maconheiros".

Claro que em um evento dessa natureza e com a quantidade de pessoas que participaram, poderiam ocorrer situaçóes difíceis de controlar. No entanto, desde o início a preocupação da diretoria da UEE e da Comissão Organizadora do Evento foi garantir um espaço amplo e democrático, onde todas as formas de expressão estivessem presentes, desde a contestação a padróes comportamentais até debates de caráter político-ideológico. Pelo que se sabe, não houve nenhum registro de brigas ou acidentes no local.

Para Ednardo, um dos músicos mais esperados e que encerrou o encontro com seu show:

\footnotetext{
Passeamos entre as barracas do imenso acampamento e vimos muita gente linda, que nos convidava pra cantar um pouco e escutar suas músicas, tomar chimarrão, vinho, rolava em alguns cantos charos dos bons, mas não vi nenhum desbunde de coisas pesadas. A juventude estava ali para mostrar que sabia se organizar por conta própria (CIO, 2007).
}

Ednardo também lembra de um show que fez em Porto Alegre, em 2001, quando um casal veio dizer a ele que tinham um filho com seu nome - Ednardo - em função de ter sido gerado no Cio da Terra. 
No mais recente show que fiz em Porto Alegre, em 2001, muitas pessoas vieram falar comigo se referindo ao Cio da Terra. Entre elas, chegou um casal com um filho de 19 pra 20 anos, dizendo que ele foi gerado no dia do meu show. Fiquei super honrado e feliz com este fato, que representa que minhas músicas fazem parte efetiva da trilha sonora e existencial de muitas pessoas (CIO, 2007).

Mas o sucesso do evento não significou que a organização do mesmo não tivesse tido grandes problemas. Inicialmente o Cio da Terra estava marcado para os dias $1^{\circ}$ a 3 de outubro. Diversos contratos já haviam sido assinados com artistas e o material de divulgação já estava circulando quando a direção da UNE remarcou a data do Congresso da entidade para os mesmos dias.

Inicialmente o III Conselho Nacional de Entidades de Base (CONEB), realizado nos dias 16 a 19 de julho de 1982, em Belo Horizonte, tinha marcado o Congresso da UNE para os dias 24 a 26 de setembro. Caberia à direção da UNE convocar um Conselho Nacional de Entidades Gerais (CONEG) para preparar o mesmo. A diretoria da UNE náo marcou o CONEG previsto e remarcou a data para uma semana após ( $1^{\circ}$ a 3 de outubro, justamente os dias em que estava marcado a realização do CIO DA TERRA) ${ }^{6}$. Sem o chamamento do CONEG, a UEE/RS e as entidades estudantis gaúchas ficaram sem a opção de ter uma instância que pudesse reverter a data. Diante desse quadro a diretoria da UEE teve de remarcar o evento para dias 29, 30 e 31 de outubro de 1982, com muitos prejuízos, o que iria refletir-se na próxima gestão, a qual herdou parte das dívidas. A remarcação da data tinha um forte conteúdo político, pois a delegação do Rio Grande do Sul, além de numerosa, era composta fundamentalmente de delegados que faziam oposição à direção da UNE à época. Possivelmente tivesse sido a delegação com maior número de delegados de oposição, sendo inclusive Aldo Fornazieri, presidente da UEE/RS, quem encabeçou a chapa de oposição em um processo de eleição congressual.

O problema da falta de datas no final do ano gerou uma situação curiosa. Quando ocorreu o evento, já havia sido escolhida a nova direção da UEE embora o evento estivesse sob responsabilidade da primeira gestão da Travessia. A eleição para a nova direção da UEE ocorreu cerca de 10 dias antes da realização do Cio da Terra, dias 20 e 21 de outubro de 1982, mesmos dias das eleições para o DCE da UFSM, da UPF e da UFPEL, sendo que em todos esses DCEs a Resistência (uma das correntes estudantis que compunha a diretoria da UEE) foi a chapa vencedora (Cláudio Ritter

\footnotetext{
${ }^{6}$ A delegação gaúcha normalmente era uma das maiores em quantidade de delegados nos Congressos da UNE e normalmente a imensa maioria dos mesmos eram de oposição à direção da entidade.
} 
Alves, Paulo Zílio e Gerson Madruga, respectivamente, foram eleitos presidentes dos DCEs). Em outras universidades (UFRGS, Unisinos) as chapas vencedoras eram vinculadas ao jornal Em Tempo, articulador de uma outra corrente estudantil (Peleia) que compunha a direção da UEE/RS.

Somente em Santa Maria a chapa vitoriosa para a UEE/RS (Travessia) ${ }^{7}$ teve 5.234 votos. Essa chapa foi eleita tendo Flávio Silveira (Em Tempo) como presidente, José Eduardo Utzig (Resistência) como vice e Nara Magalhães (Resistência) como Secretária $\mathrm{Geral}^{8}$. A outra chapa que concorreu foi a chapa Alicerce, vinculada à Convergência Socialista. O resultado para as eleiçóes da UEE, em Pelotas, foi: Travessia, 2.196 votos e Alicerce, 364 .

Embora não tenhamos os números finais exatos, esses dados (Santa Maria e Pelotas) já indicam a grande diferença de votos entre as duas chapas que disputaram a entidade.

A grande votação que a chapa Travessia teve junto aos estudantes gaúchos, em grande medida, era o reflexo do processo de mobilização envolvendo a organização do Cio da Terra. A busca de recursos para a organização do evento, bem como para a organização de caravanas locais que se deslocariam até Caxias, mobilizou o conjunto das entidades estudantis gaúchas por praticamente todo o ano de 1982. Em função da remarcação da data, e na medida em que alguns contratos já estavam assinados (Grupo Tarancón, Cida Moreira, Premeditando o Breque, etc.), não restou outra alternativa senão a organização de um conjunto de shows com esses artistas nas principais cidades do estado (Porto Alegre, Pelotas, Santa Maria, entre outros).

Embora o Cio da Terra tenha tido uma enorme repercussão no movimento estudantil gaúcho, não podemos colocá-lo na condição de uma atividade inédita no movimento estudantil brasileiro. Nos anos de 1979 e 1980 foi realizado algo semelhante em Fortaleza, denominado de Massafeira Livre. No ano seguinte, 1981, houve o Encontro da Juventude Mineira, também atividade que teve características muito parecidas. Segundo o blog Zeca Zines (administrado por Aura Edições Musicais), referindo-se a esses eventos,

\footnotetext{
${ }^{7}$ A gestão 82/83 também adotou o nome de Travessia e era composta majoritariamente pelos dois setores que compuseram a gestão anterior (Resistência e Peleia) com mais algumas tendências que se juntaram à chapa.

${ }^{8}$ Existe dúvida em relação ao cargo ocupado por Nara. Outro nome citado como Secretário Geral nessa gestão é o de Renato Azambuja, estudante de medicina da UFRGS.
} 
Cada um destes eventos expóe e ressalta características próprias de cada regiấo, e reúne multidão de pessoas de todas idades em um palco/platéia aberto às expressóes de todos, às premências da "juventude" de diversas faixas etárias querendo se expressar, após abafado período de silêncios impostos pela ditadura (CIO, 2007).

E especificamente no que diz respeito ao Cio da Terra, lembra que

Nos debates que aconteceram no Cio da Terra, assim como nos outros eventos, tinham vários itens: Música, Teatro, Cinema, Dança, Literatura, Poesia, Artes Plásticas, Cultura Popular, Cultura Alternativa, Folclore, Artesanato, Comidas Típicas, etc. No Cio da Terra os debates foram ampliados incluindo temas sobre Ecologia, Educação, TV, Negros, Índios, Mulheres, Alimentação Natural, Camping, Drogas, Política, Sexualidade, etc. (CIO, 2007).

Podemos perceber que muitos dos debates realizados no Cio da Terra ainda são atuais. No entanto, não podemos de forma apressada dizer que nada mudou daquele momento para hoje ou que as reivindicações permanecem as mesmas. É necessária uma contextualização histórica para compreendermos até mesmo o impacto que o evento exerceu sobre aquela geração. Se é verdade que a discussão sobre liberação da maconha esteve presente nos debates organizados pelo evento, por exemplo, não podemos esquecer que na época o uso da mesma era considerado crime sujeito à prisão. De forma similar, a luta das mulheres por igualdade de condiçóes, ainda presente em nossa sociedade, tinha barreiras bem maiores que as atuais. Como exemplo, podemos lembrar de uma ocupação de mulheres à Casa do Estudante Universitário (CEU) da UFPEL, onde as mesmas não podiam nem mesmo entrar, muito menos residir. $\mathrm{O}$ fato gerador da ocupação foi a proibição da mãe de um aluno do curso de Veterinária entrar na CEU, que queria visitá-lo pois seu filho tinha quebrado a perna e mesmo assim foi impedida pela segurança da casa.

A discussão a respeito da liberdade em um contexto de rompimento com a ditadura foi considerada como um dos elementos centrais que permitiu que o Cio da Terra se realizasse naquele contexto e com a força que teve.

[...] aquilo era uma grande conquista para a juventude. Cada geração tem a sua tarefa. A daquela era decidir se queria ser livre ou seguir os valores que a ditadura havia incutido. Acho que falta para a juventude de hoje, controlada pelo marketing, mas que clama por uma ideologia, ter essa discussão básica. Para onde ir? (CASTRO apud ANDRADE, 2012, p. 17). 
As características de um modelo de sociedade que beirava ao fascismo não estavam presentes apenas nas estruturas militares ou nos aparatos coercitivos do Estado. Culturalmente vivíamos um período de grande repressão sexual. No final dos anos 70 e início dos anos 80 ainda era comum homens que mataram suas mulheres e/ou companheiras serem inocentados nos tribunais alegando serem "crimes de honra". O controle do corpo, da sexualidade, era um ingrediente político importante do controle da sociedade. Até mesmo uma obra de Picasso foi proibida no Brasil por ser considerada pornográfica. A censura não preocupava-se apenas com questóes políticas, mas também com questóes comportamentais ou morais. Frequentemente as prostitutas eram levadas em camburóes da polícia em São Paulo e cidades maiores em nome de uma "limpeza moral".

É nesse contexto de repressão cultural e dentro do processo de expansão de uma indústria cultural massiva e alienante que vinha se instalando no país rapidamente no final da década de 70 , que também surge aquilo que era designado como "cultura marginal", "arte marginal", "contracultura" ou "cinema marginal". A busca de alternativas vinculadas à liberação de costumes, à construção de uma nova sociabilidade, onde movimentos pacifistas, ecologistas e ambientais se articulam com lutas políticas e com movimentos que buscam a livre expressão e organização da sociedade (mulheres, negros, gays, etc.). Somente nesse contexto é que pode ser entendido o I Encontro da Juventude Gaúcha. E também nesse contexto é que talvez possa ser melhor compreendida a fala de Abner Gomes (2011) (referindo-se ao Cio da Terra), de que "[...] acho que não teve um segundo porque não tinha como haver".

Renato da Silva Della Vechia é professor do Programa de PósGraduação em Políticas Públicas da Universidade Católica de Pelotas. E-mail: rdellavechia@gmail.com

\section{Referências}

ANDRADE, Andrei. Cio da Terra: Primeiro e Único. Revista O Caxiense, Caxias do Sul, n. 151, p. 11-17, out. 2012.

BERLINCK, Manoel Tosta. O Centro Popular de Cultura da UNE. Campinas: Editora Papirus, 1984. CIO da Terra - 25 anos. Rádio Jornal Canal Zeca Zines. 31 out. 2007. Disponível em: <http://zecazines.blogspot.com.br/2007/10/cio-da-terra-25-anos.html>. Acesso em: 04 ago. 2014. 
DIRCEU, José; PALMEIRA, Vladimir. Abaixo a Ditadura: O Movimento de 68 contado por seus líderes. Rio de Janeiro: Ed. Garamond, 1998.

EU Fui ao Cio da Terra: comunidades. Moderador: Celso Dias. 2011. Disponível em: <http://www.orkut.com.br/Main\#Community?cmm=5820198>. Acesso em: 12 jan. 2011.

GASTAL JUNIOR, João Carlos. Entrevista II. [2011]. Entrevistador: Renato da Silva Della Vechia. 2011.

GOMES, Abner Jandir Pífero. Entrevista III. [2011]. Entrevistador: Renato da Silva Della Vechia. 2011.

HOLLANDA, Heloisa Buarque de. Impressóes de Viagem. São Paulo: Ed. Brasiliense, 1981.

OLIVEIRA, José Alberto Saldanita de. A Mitologia Estudantiı. Maceió: SERGASA, 1994.

ORTIZ, Renato. Cultura Popular: organização e ideologia. Caderno de Opinião, n. 12, jul. 1979.

SARAH, A. Cio da Terra: O Woodstock Gaúcho de 1982. Poeta de Guardanapo, 2013. Disponível em: <http://poetadeguardanapo.blogspot.com.br/2013/12/cio-da-terra-o-woodstock-gaucho-de1982.html>. Acesso em 04 de agosto de 2014.

SILVA, Justina Ivã de A. Estudantes e Política: Estudo de um movimento (RN 1960-1969). São Paulo: Cortez Editora, 1989.

SOUSA, Janice Tirelli Ponte de. Reinvençóes da Utopia: A militância política de jovens nos anos 90. São Paulo: Hacker Editores, 1999.

VARGAS, Pepe. Entrevista I. [2011]. Entrevistador: Renato da Silva Della Vechia. 2011.

VÁRIOS Autores. Brasil Revolucionário, n. 1, mar.-abril.1989.

VECHIA, Renato da Silva Della. O Ressurgimento do Movimento Estudantil Gaúcho no processo de Redemocratização: As Tendências Estudantis e seu papel (1977/1985). 2011. 411f. Tese (Doutorado em Ciência Política) - Programa de Pós Graduação em Ciência Política, Universidade Federal do Rio Grande do Sul, Porto Alegre, 2011.

Texto recebido em 30 de julho de 2014. Aprovado em 12 de agosto de 2014. 